\title{
Insights in luteovirid structural biology guided by chemical cross-linking and high resolution mass spectrometry
}

\author{
Mariko M. Alexander ${ }^{\mathrm{a}, \mathrm{b}}$, Jared P. Mohr ${ }^{\mathrm{c}}$, Stacy L. DeBlasio ${ }^{\mathrm{d}}$, Juan D. Chavez ${ }^{\mathrm{c}}$, \\ Veronique Ziegler-Graffe, Veronique Brault ${ }^{\mathrm{f}}$, James E. Bruce ${ }^{\mathrm{c}}$, Michelle (Cilia) Heck ${ }^{\mathrm{a}, \mathrm{b}, \mathrm{d}, *}$ \\ a School of Integrative Plant Science, Plant Pathology and Plant Microbe Biology Section, Cornell University, Ithaca, NY, USA \\ b Boyce Thompson Institute, Ithaca, NY, USA \\ ${ }^{c}$ Department of Genome Sciences, University of Washington, Seattle, WA, USA \\ d USDA-Agricultural Research Service, Emerging Pests and Pathogens Research Unit, Robert W. Holley Center for Agriculture and Health, Ithaca, NY, USA \\ e Université de Strasbourg, CNRS, IBMP UPR 2357, F-67000 Strasbourg, France \\ ${ }^{\mathrm{f}}$ INRA-UDS, Colmar, France
}

\begin{abstract}
A B S T R A C T
Interactions among plant pathogenic viruses in the family Luteoviridae and their plant hosts and insect vectors are governed by the topology of the viral capsid, which is the sole vehicle for long distance movement of the viral genome. Previous application of a mass spectrometry-compatible cross-linker to preparations of the luteovirid Potato leafroll virus (PLRV; Luteoviridae: Polerovirus) revealed a detailed network of interactions between viral structural proteins and enabled generation of the first cross-linking guided coat protein models. In this study, we extended application of chemical cross-linking technology to the related Turnip yellows virus (TuYV; Luteoviridae: Polerovirus). Remarkably, all cross-links found between sites in the viral coat protein found for TuYV were also found in PLRV. Guided by these data, we present two models for the TuYV coat protein trimer, the basic structural unit of luteovirid virions. Additional cross-links found between the TuYV coat protein and a site in the viral protease domain suggest a possible role for the luteovirid protease in regulating the structural biology of these viruses.
\end{abstract}

\section{Introduction}

Viruses in the family Luteoviridae, referred to in this paper as luteovirids, are plant pathogenic, icosahedral viruses with a monopartite, positive-sense, single stranded RNA genome. With the exception of viruses in the genus Enamovirus, luteovirids are transmitted exclusively by aphids in a persistent, circulative manner and are restricted to the plant vascular tissue, or phloem, in a natural infection. Luteovirids have an extensive host and geographical range, with six new species characterized in 2016 alone (Bag et al., 2015; Bejerman et al., 2016; Chen et al., 2016; Ibaba et al., 2017; Lotos et al., 2016; Sharman et al., 2016; Villamor et al., 2016). These viruses are important pathogens of many major crops, including small grains (yellow dwarf viruses; Luteoviridae: Polerovirus and Luteovirus), brassicas (Turnip yellows virus, TuYV; Luteoviridae: Polerovirus), sugarcane (Sugar- cane yellow leaf virus, SCYLV; Luteoviridae: Polerovirus), potato (Potato leafroll virus; Luteoviridae: Polerovirus), and soybean (Soybean dwarf virus, SbDV; Luteoviridae: Luteovirus). Management of these pathogens relies on cultural practices and control of the aphid vectors, as no chemicals means are available to target luteovirids directly. However, insecticide resistance and environmental impact are significant and growing concerns.

The luteovirid genome is $5-6 \mathrm{kB}$ in length and includes five to nine overlapping open reading frames depending on genus. Luteovirids have a non-enveloped, icosahedral capsid with $\mathrm{T}=3$ symmetry, which is comprised primarily of the $20-25 \mathrm{kDa}$ coat protein. Sporadic readthrough of an amber stop codon following the coat protein gene leads to translation of a $25-50 \mathrm{kDa}$ C-terminal extension known as the readthrough domain (Bahner et al., 1990; Dinesh-Kumar et al., 1992; Reutenauer et al., 1993; Veidt et al., 1988). The resulting readthrough

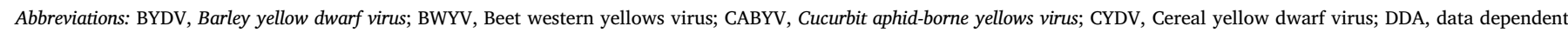

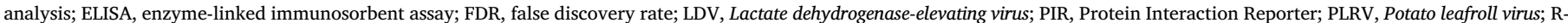

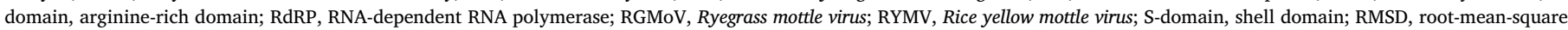
deviation; SbDV, Soybean dwarf virus; SCYLV, Sugarcane yellow leaf virus; SeMV, Sesbania mosaic virus; TCV, Turnip crinkle virus; TuYV, Turnip yellows virus

* Corresponding author at: Boyce Thompson Institute, 533 Tower Road, Ithaca, NY, 14853 USA.

E-mail addresses: mlc68@cornell.edu, michelle.cilia@ars.usda.gov (M.C. Heck). 
protein is believed to be incorporated in the capsid with a low but undetermined frequency (Brault et al., 1995; Cheng et al., 1994). Interestingly, the full-length readthrough protein can be readily detected by western blot in protein extracts from luteovirid-infected plants; however, the signal for the full-length protein is weak or absent in purified virions (Bahner et al., 1990; Brault et al., 1995; Bruyère et al., 1997; Filichkin et al., 1994; Jolly and Mayo, 1994; Wang et al., 1995). Instead, one or more lower molecular weight bands attributed to C-terminal truncation(s) of the readthrough protein can be detected. Truncated readthrough protein is sporadically detectable in whole protein extracts. Recently, a function in systemic movement was demonstrated for the truncated readthrough protein of Cucurbit aphidborne yellows virus (CABYV; Luteoviridae: Polerovirus) (Boissinot et al., 2014), indicating that readthrough protein truncation is not simply a byproduct of host defense or virus purification. Although the protein(s) responsible for this cleavage are unknown, it has been suggested that the viral protease, encoded by ORF 1 and referred to as the P1 protease hereafter, may be involved (Boissinot et al., 2014). Currently, the only experimentally verified function of the $\mathrm{P} 1$ protease is in processing of the P1 polyprotein (Li et al., 2007; Li et al., 2000).

Early studies in luteovirid structural biology included epitope mapping of the PLRV virion, identifying twelve epitopes within the PLRV coat protein (Torrance, 1992). Several other studies assessed the effect of targeted mutations in the coat protein and readthrough domain on capsid assembly, aphid transmission, viral replication, and systemic movement (Brault et al., 2003; Bruyère et al., 1997; Hipper et al., 2014; Kaplan et al., 2007; Lee et al., 2005; Peter et al., 2009, 2008). These studies enabled the generation of a detailed functional map of the coat protein; however, the complete lack of available crystal structures for any luteovirid virion or structural protein has been a significant hurdle to link structure to function. The first computational model of a luteovirid coat protein was obtained for PLRV in 2001, by homology modeling against the crystal structure of other icosahedral plant viruses, despite a less than $30 \%$ sequence identity between the coat proteins of PLRV and the nearest relative with an available crystal structure at the time (Terradot et al., 2001). Like the coat proteins of many other icosahedral viruses, the PLRV coat protein can be subdivided into a shell (S-) domain, which forms the capsid surface, and an arginine-rich (R-) domain, which likely interacts with viral nucleic acid inside the capsid. Alternate luteovirid coat protein monomer and trimer models have since been proposed for PLRV and TuYV based on new mutational analyses, cross-linking data, and alternate computational modeling (Brault et al., 2003; Chavez et al., 2012; DeBlasio et al., 2015a). However, without a crystal structure for any luteovirid, full validation of these models remains impossible. The recalcitrance of luteovirids to crystallization is likely due in part to the highly disordered readthrough domain projecting outward from the capsid surface, which may not uniformly adopt an ordered conformation (Chavez et al., 2012). Computational modeling of the readthrough domain has also proved difficult, as it does not bear homology to any protein for which a crystal structure is available, and de novo modeling is also negatively affected by the high degree of disorder predicted in this domain (Chavez et al., 2012). Luteovirid structural biology studies are further hampered by their phloem limitation, as phloem cells are relatively low in abundance and are difficult to separate from other tissues (DeBlasio et al., 2016). Further advances in luteovirid structural biology could lead to new strategies for management of these pathogens. In particular, luteovirid-aphid vector interactions are known to be governed by capsid topology (Brault et al., 1995; Bruyère et al., 1997; Chavez et al., 2012; Chay et al., 1996; Gray et al., 2014; Kaplan et al., 2007; Lee et al., 2005; Linz et al., 2015; Peter et al., 2008; Reinbold et al., 2003; Ziegler-Graff et al., 1996).

Protein Interaction Reporter (PIR) technology uses mass spectrometry-cleavable cross-linkers to detect direct protein-protein interactions, both in vivo and in vitro (Chavez et al., 2012; Tang et al., 2005; Weisbrod et al., 2013). The unique composition of the PIR cross-linker permits large-scale identification of cross-linked peptides, including the identity of specific cross-linked residues. Using these cross-linked residues and the known length of the PIR cross-linker, protein-protein interaction topologies, or interaction interfaces, can be computationally modeled. The usefulness of PIR technology in probing both the structural biology and virus-host interactions of luteovirids has already been shown with PLRV, generating not only the first large-scale map of direct luteovirid interactions, but also the first predictions of specific PLRV-binding sites on several host proteins (Chavez et al., 2012; DeBlasio et al., 2015a). Although extensive, these data were limited to a single virus species. As PIR had never before been applied to two species within the same genus, it was unknown to what extent crosslinks were likely to be conserved. If cross-linking data from one species can reasonably be extended to its relatives, the potential significance of a single PIR experiment would be much greater. To begin to address this question, and to expand on our previous studies, we applied PIR technology to probe the structural biology of TuYV, a related pathogen of plants in the Brassicaceae. Our results enable the generation of new structural protein models that are supported by cross-linking data as well as previous literature, and represent the first comparison of data derived from mass specrometry-compatible cross-linkers between related viruses

\section{Materials and methods}

\subsection{Preparation of plant material}

$N$. benthamiana leaves were inoculated by infiltration with $A$. tumefaciens C58C1 (Holsters et al., 1980) containing a cDNA clone of TuYV (Leiser et al., 1992). Infiltrated leaves were harvested six to eight days after inoculation and immediately frozen in liquid nitrogen. Leaf tissue was stored frozen until use.

\subsection{Virus purification and aphid transmission assays}

TuYV was purified from infected $N$. benthamiana leaves by sucrose density centrifugation as previously described (van den Heuvel et al., 1991), and virus was recovered after the $30 \%$ sucrose cushion. Aphid transmissibility of virus used for cross-linking was verified by feeding Myzus persicae for $24 \mathrm{~h}$ on membranes containing $50 \mu \mathrm{g}$ of purified TuYV in a total volume of $500 \mu \mathrm{l}$ of a nutrient solution, or nutrient solution alone as a negative control (Kim and Jander, 2007). Ten aphids per plant were transferred to five young A. thaliana plants per treatment, and allowed to feed for $72 \mathrm{~h}$ before they were removed by fumigation. Infection status of recipient plants was analyzed three weeks after inoculation by double antibody sandwich enzyme-linked immunosorbent assay (DAS-ELISA) using a commercially available antiTuYV antibody set (Loewe Biochemica GmbH). Young leaf tissue was collected and homogenized in $200 \mu \mathrm{L}$ of phosphate-buffered saline per $12 \mathrm{mg}$ of tissue, using a Mixer Mill 400 (Retsch GmbH). Samples with a blank-subtracted $\mathrm{Abs}_{405}$ value greater than 0.5 were considered positive. Samples from a plant previously confirmed to be infected with TuYV were used as a positive control.

\subsection{Cross-linking of purified virus}

Synthesis of the biotin aspartate proline-PIR (BDP-NHP) cross-linker was carried out as previously described (Weisbrod et al., 2013). A total of $1.3 \mathrm{mg}$ of purified TuYV was diluted to a volume of $250 \mu \mathrm{L}$ with $100 \mathrm{mM}$ citrate buffer, $\mathrm{pH} 6.0$, containing $0.5 \%$ ethanol. A $250 \mathrm{mM}$ stock solution of PIR cross-linker in methanol was added to samples to a final concentration of $1 \mathrm{mM}$, and the sample was incubated at room temperature with vigorous shaking for one hour. Urea was then added to a final concentration of $8 \mathrm{M}$. Reduction and alkylation, protein digestion, and desalting were performed as previously described for PLRV (DeBlasio et al., 2015a). 
Peptide samples were fractionated by strong cation exchange (SCX) chromatography using an Agilent 1200 HPLC system equipped with a Phenomenex Luna SCX column. A binary linear gradient consisting of buffer A (5 mM KH${ }_{2} \mathrm{PO}_{4}$, pH 2.6, 30\% acetonitrile [ACN]) and buffer B (5 mM KH $2 \mathrm{PO}_{4}, \mathrm{pH} 2.6,30 \% \mathrm{ACN}, 350 \mathrm{mM} \mathrm{KCl}$ ) was applied at a flow rate of $1.5 \mathrm{~mL} / \mathrm{min}$ for $97.5 \mathrm{~min}$ as follows: $0 \% \mathrm{~B}$ at $0 \mathrm{~min}, 5 \% \mathrm{~B}$ at $7.5 \mathrm{~min}, 60 \% \mathrm{~B}$ at $47.5 \mathrm{~min}, 100 \% \mathrm{~B}$ at $67.5 \mathrm{~min}, 100 \% \mathrm{~B}$ at $77.5 \mathrm{~min}$, $0 \% \mathrm{~B}$ at $77.51 \mathrm{~min}, 0 \% \mathrm{~B}$ at $97.5 \mathrm{~min}$. Fractions were taken every $5 \mathrm{~min}$ starting at $17.5 \mathrm{~min}$, and fractions were pooled ( 6 total) as follows: $1-5$, $6-7,8,9,10,11-14$. Fraction pools were then dried to a final volume of $\sim 2 \mathrm{~mL}$ in a vacuum centrifuge and adjusted to a $\mathrm{pH}$ of 8.0 with $1.5 \mathrm{M}$ $\mathrm{NaOH}$. These samples were then enriched by incubation with Ultralink monomeric avidin (ThermoFisher). Briefly, $100 \mu \mathrm{L}$ of avidin resin was added to each fraction and samples were incubated at room-temperature with mixing for $1 \mathrm{~h}$. Cross-linked peptides were washed on the avidin matrix using $100 \mathrm{mM} \mathrm{ABC}$, and subsequently eluted from the avidin resin by the addition of $70 \%$ acetonitrile- $0.5 \%$ formic acid.

\subsection{Generation of a stage I database}

To maximize our ability to identify cross-links in TuYV, a stage I database enriched for PIR-reactive proteins was generated (DeBlasio et al., 2015a; Navare et al., 2015) for searching of avidin-enriched fractions using $0.5 \mathrm{mg}$ of the same purified TuYV used in Section 2.3. The stage I database approach enriches for proteins that have reacted with the cross-linker by incubating the cross-linked protein sample with monomeric avidin prior to trypsin digestion. Protein samples are then eluted from the avidin resin using a solution containing $8 \mathrm{M}$ urea, $2 \mathrm{mM}$ biotin in $100 \mathrm{mM} \mathrm{ABC}$. Following elution the sample is diluted by a factor of 10 to bring the urea concentration to less than $1 \mathrm{M}$ and the reduction, alkylation and digestion are performed as described in Section 2.2.

Peptides resulting from digestion of avidin enriched proteins were analyzed using a Thermo n-LC coupled to a Q Exactive Plus mass spectrometer. Peptides were fractionated over a $60 \mathrm{~cm}$ x $75 \mu \mathrm{m}$ inner diameter fused silica analytical column packed with ReproSil-Pur C8, $5 \mu \mathrm{m}$ diameter, $120 \AA$ A pore size particles by applying a linear gradient from $98 \%$ solvent A ( $0.1 \%$ formic acid in water), $2 \%$ solvent B $(0.1 \%$ formic acid in acetonitrile) to $70 \%$ solvent A, 30\% solvent B over either $90 \mathrm{~min}$ at a flow rate of $300 \mathrm{~nL} / \mathrm{min}$. Peptides eluting from the column were ionized by ESI by applying a voltage of $2-2.5 \mathrm{kV}$ to the laser pulled fused silica spray tip at the end of the column. The mass spectrometer was operated using a data dependent analysis (DDA) method performing one high resolution (70,000 resolving power (RP) at $m / z 200$ ) MS1 scan from 400 to $2000 \mathrm{~m} / z$ followed by MS2 (17,500 RP) on the 20 most abundant ions detected in the MS1. Settings for MS2 analysis included at automatic gain control target value of 50,000 ions, a maximum ion accumulation time of $50 \mathrm{~ms}$, an isolation window of $1.6 \mathrm{~m} / \mathrm{z}$ and a normalized collision energy of 25. Ions selected for MS2 were dynamically excluded from further selection for $30 \mathrm{~s}$. A stage I database was generated by searching the resulting spectra with Comet against a concatenated target-decoy database containing proteins from $N$. benthamiana and TuYV. At a 1\% false discovery rate (FDR), 106 unique $N$. benthamiana proteins had at least 1 peptide-spectrum match. These proteins were merged with all 12 proteins from the TuYV database, yielding the complete stage 1 database.

\subsection{ReACT}

Enriched cross-linked peptide samples were resuspended in $0.1 \%$ formic acid and analyzed using a Waters nano-Acquity UPLC system coupled to a Velos-FTICR mass spectrometer. Peptides were fractionated using a $60 \mathrm{~cm} \times 75 \mu \mathrm{m}$ inner diameter fused silica analytical column packed with ReproSil-Pur C8, $5 \mu \mathrm{m}$ diameter, $120 \AA$ pore size particles by applying a linear gradient from $95 \%$ solvent A, $5 \%$ solvent B to $60 \%$ solvent A, $40 \%$ solvent B over either 120 or 240 min at a flow rate of $300 \mathrm{~nL} / \mathrm{min}$. The mass spectrometer was operated utilizing a Real-time Analysis for Cross-linked peptide Technology (ReACT) method (Weisbrod et al., 2013), where ions with a charge state of four or greater were selected for high resolution MS2 analysis in the ICR cell where an "on-the-fly" check of the observed fragment ion masses against the PIR mass relationship (Mass Precursor $=$ Mass Reporter Ion + Mass Peptide $1+$ Mass Peptide 2) is performed. Masses that satisfied the PIR relationship within a tolerance of $20 \mathrm{ppm}$ mass error triggered subsequent low resolution MS3 analyses of the released crosslinked peptide ions.

\subsection{Mass spectrometry data analysis}

The database for searching the stage I sample consisted of version 0.4.4 of the predicted $N$. benthamiana proteome from the Sol Genomics Network (solgenomics.net), in addition to the proteome of the TuYV infectious clone used in this study, which was manually curated in house.

Data generated from ReACT analyses was searched using Comet version 2016.01 rev. 2 with the stage I database. Search settings included a precursor mass tolerance of $20.0 \mathrm{ppm}$, standard C13 error, tryptic peptides with up to two missed cleavages, and a fragment mass tolerance of $1.005 \mathrm{Da}$. The mass modifications included: a variable modification of oxidation on Met (15.9949 Da), a variable mod of acetylation on Lys (42.010565 Da), and a required modification of the cross-linker stump mass on Lys (197.032422 Da). Peptides are sorted by ascending e-value, and the FDR was calculated as the ratio of twice the number of decoy hits divided by the total number of hits at a given evalue. Peptides were filtered to a $1 \%$ FDR, yielding 261 unique peptidespectrum matches.

\subsection{Modeling of the coat protein trimer}

The structure of the TuYV coat protein monomer was modeled by the I-TASSER server (Yang et al., 2015). The most recent model of the PLRV coat protein (DeBlasio et al., 2015a) was included as a usersupplied input for multi-template threading. The top five I-TASSER models were subjected to analysis with the R-package XLmap (Schweppe et al., 2016) to assess their fit with cross-linking data for TuYV and PLRV, using a maximum distance of $50 \AA$ for both contact mapping and contact map score (CMscore) calculation. The top-ranking I-TASSER model had the best CMscore of the five coat protein models, and was therefore used for all subsequent modeling. The root-meansquare deviation (RMSD) of atomic positions in the PLRV and TuYV coat protein S-domains (designated as amino acids 42-208 and 36-202, respectively) was calculated by Molsoft (Molsoft LLC) by weighted iterative superposition. Modeling of the coat protein trimer was performed using SymmDock (Schneidman-Duhovny et al., 2005), with a 3-fold order of symmetry. The unambiguous homodimer cross-link found for the TuYV coat protein, as well as three other homologous homodimer cross-links found for PLRV, were supplied as distance constraints, with a maximum allowable distance of $35 \AA$ between cross-linked residues. Sidechain and flexible backbone refinement of the 77 models produced by SymmDock was performed by SymmRef (Mashiach-Farkash et al., 2011). As SymmDock's distance calculations are strictly Euclidean and may pass through the interior of a protein, XWALK was used to calculate the solvent accessible distance between residues used as distance constraints (Kahraman et al., 2011). Images of the monomer and trimer models were generated in MolSoft (MolSoft LLC), and final figures assembled in Adobe Photoshop (Adobe Systems).

\subsection{SDS-PAGE and detection of PLRV readthrough protein isoforms}

$N$. benthamiana leaves were inoculated with an infectious clone of PLRV by agroinfiltration (DeBlasio et al., 2015b). Infiltrated leaves were harvested and frozen three days after inoculation. Frozen tissue 
was roughly ground with mortar and pestle without being allowed to thaw. PLRV virions were isolated from ground tissue, and their aphid transmissibility verified, as previously described (Chavez et al., 2012).

Five micrograms of purified PLRV were mixed with an equal volume of 2X Laemmli Sample Buffer (Bio-Rad) containing 5\% beta-mercaptoethanol, and incubated at 98C in a thermocycler (Bio-Rad) for five minutes prior to separation on a $10 \%$ Mini-Protean TGX SDS-polyacrylamide gel (Bio-Rad) in a Mini-Protean Tetra cell (Bio-Rad). Crude protein extracts from a PLRV agroinfiltrated and a mock infiltrated $N$. benthamiana leaf, also diluted with an equal volume of Laemmli buffer, were included as positive and negative controls, respectively. The Precision Plus Protein Kaleidoscope Ladder (Bio-Rad) was included for estimation of band molecular weights. Western blotting for detection of PLRV coat protein/readthrough protein was performed as previously described (DeBlasio et al., 2015b). The blot was imaged using a document scanner and brightness/contrast adjusted in Adobe Photoshop (Adobe Systems).

\subsection{Analysis of potential $P 1$ cleavage sites in the luteovirid readthrough protein}

Luteovirid readthrough protein and P1 polyprotein sequences were downloaded from NCBI on November 22, 2016 and sorted by virus species. A consensus readthrough protein sequence for each species was built using MUSCLE (http://www.ebi.ac.uk/Tools/msa/muscle/), the Los Alamos National Laboratory Consensus Maker tool (https://www. hiv.lanl.gov/content/sequence/CONSENSUS/consensus.html) and manual curation. The sequences for the TuYV infectious clone used in these studies were used as the representative sequences for TuYV, and TuYV was considered as a species distinct from the related Beet western yellows virus (BWYV; Luteoviridae: Polerovirus) as per the most recent International Committee on Taxonomy of Viruses (ICTV) Release (Adams et al., 2016). Multiple sequence alignment of the P1 polyprotein consensus sequences was performed by MUSCLE. A simple script using BioPython (Chapman and Chang, 2000) was used to identify potential P1 cleavage sites in each consensus sequence and calculate the molecular weight of the truncated product. The Gaussian kernel density plot summarizing the cleavage site positions was generated in $\mathrm{R}$ using the ggplot2 package, using a smoothing bandwidth equal to one-half of the standard deviation of the smoothing kernel (Wickham, 2009).

\section{Results and discussion}

\subsection{Purified TuYV virions were transmissible by aphids}

TuYV virions were purified by sucrose density purification from Nicotiana benthamiana leaves 6-8 days after infiltration with a wild-type TuYV clone (Veidt et al., 1992). To verify the integrity and infectivity of purified virions, the aphid transmissibility of the purified virus preparation was tested by feeding $M$. persicae on membranes containing purified virus diluted with a nutrient solution. Of the five A. thaliana plants colonized with aphids fed on membranes containing purified TuYV, one died prior to sampling, and the remaining four gave clear positive ELISA readings (data not shown). All five plants colonized by aphids fed on virus-free nutrient solution gave negative ELISA readings.

\subsection{PIR enabled the identification of TuYV cross-linked peptides}

After verifying the integrity and infectivity of purified virions, $1.3 \mathrm{mg}$ of the purified sample was subjected to PIR cross-linking and mass spectrometry. Two cross-links between reactive lysines on the TuYV coat protein were observed, between K150 and K179, and an unambiguous homodimer from K179-K179 (Table 1). Strikingly, all coat protein - coat protein cross-links observed in TuYV were also observed in PIR cross-linked PLRV samples, as these lysines are conserved (DeBlasio et al., 2015a). In addition to representing the first cross-linking data for TuYV, these results also show that PIR data are applicable to related species with good conservation of lysine residues.

Unexpectedly, two additional cross-links were found between the coat protein and a viral non-structural protein. Two reactive lysines in the TuYV coat protein (K179 and K195) were found cross-linked to a reactive lysine in TuYV ORF 1 . The residue in ORF 1 could not be confidently assigned to a single viral protein, as this residue is present in both the viral P1 polyprotein, and in a fusion protein generated by a frameshift (the P1-P2 fusion protein) which contains the viral RNAdependent RNA polymerase (RdRP). Although several variants of another peptide in ORF 1 could be detected during creation of the stage I database, these peptides are also shared between P1 and the P1P2 fusion protein. No peptides unique to either P1 or the P1-P2 fusion protein were detected in the stage I database sample. However, the ORF 1 lysine found cross-linked to the TuYV coat protein is located near the center of the $\mathrm{P} 1$ serine protease domain. The $\mathrm{P} 1$ protease is responsible for processing of the $\mathrm{P} 1$ polyprotein by cleavage at a site $\mathrm{N}$-terminal and a site C-terminal to the protease domain. While it cannot be ruled out that either the immature polyprotein or the P1-P2 fusion protein interact with the TuYV coat protein, the location of the reactive lysine residue as well as the high efficiency of the P1 protease even when expressed separately in insect cells suggests that the coat protein is most likely to interact with the free, mature protease (Li et al., 2000).

\subsection{Modeling of the TuYV coat protein monomer}

The TuYV coat protein monomer was modeled by multi-template threading with the I-TASSER server, using the PLRV coat protein model as an additional user-supplied template (DeBlasio et al., 2015a; Yang et al., 2015). The PLRV coat protein was the top template for threading, with $100 \%$ coverage and over $60 \%$ identity, followed by the crystal structures of the Ryegrass mottle virus (RGMoV; Unclassified: Sobemovirus) and Turnip crinkle virus (TCV; Tombusviridae: Carmovirus) coat proteins. The five top I-TASSER models were evaluated using XLmap, an $\mathrm{R}$ package, to assess which models best matched the cross-linking data (Fig. 1). XLmap constructs a contact map showing the distance between every pair of residues in the protein, then maps the crosslinking data onto the contact map and calculates the CMscore, which measures the goodness of fit between the cross-linking data and the model, where a lower score indicates a better fit (Schweppe et al., 2016). Due to the high degree of homology between the TuYV and PLRV coat proteins (RMSD $=0.82 \AA$ for the S-domains), including near-perfect conservation of reactive lysine residues, the TuYV coat protein models were evaluated for goodness of fit both with the only potentially intra-protein cross-link found for TuYV (K150-K179) and with cross-links homologous to eight others previously found for PLRV (Supplementary Table S1). Model rankings relative to one another were the same regardless of which set of cross-links were used for analysis. The top-ranking I-TASSER model also had the lowest CMscore and a contact map most similar to the most recently published PLRV monomer (Fig. 1) (DeBlasio et al., 2015a), and was therefore used for the remainder of the modeling in this study. In agreement with other icosahedral coat protein structures, the S-domain of the TuYV monomer consists primarily of an eight-stranded beta jelly-roll, as previously postulated for luteovirids (Chavez et al., 2012; DeBlasio et al., 2015a; Qu et al., 2000; Rossmann, 2013; Terradot et al., 2001). The argininerich, N-terminal region of the coat protein, hypothesized to interact with the viral genome, lines the underside of the S-domain and is predicted to extend into the capsid interior.

\subsection{Cross-linking-assisted modeling of the TuYV coat protein trimer}

One TuYV coat protein cross-link, K179-K179, was confidently ascribed to an intermolecular-coat protein interaction (Table 1). This was the only cross-link from these data used for modeling of the TuYV 
Table 1

Intra-virus cross-links found in purified TuYV

\begin{tabular}{|c|c|c|c|c|c|}
\hline Protein1 & Protein2 & Peptide $1^{\mathrm{a}}$ & Peptide $2^{\text {a }}$ & FDR $1^{\text {b }}$ & $\mathrm{FDR}^{\mathrm{b}}$ \\
\hline TuYV CP/RTP & TuYV CP/RTP & TINK.FGITK $_{150}$ PGK.RAFT & DQFR.ILYK $_{179}$ GNGSSSIAGSFR.IAGS & $0.00 \mathrm{E}+00$ & $0.00 \mathrm{E}+00$ \\
\hline TuYV CP/RTP & TuYV CP/RTP & DQFR.ILYK $_{179}$ GNGSSSIAGSFR.IAGS & DQFR.ILYK $_{179}$ GNGSSSIAGSFR.IAGS & $0.00 \mathrm{E}+00$ & $0.00 \mathrm{E}+00$ \\
\hline TuYV CP/RTP & TuYV P1 & 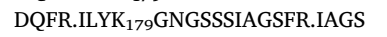 & AEFK.TIAK $_{284}$ SDK.GDVT & $0.00 \mathrm{E}+00$ & $0.00 \mathrm{E}+00$ \\
\hline TuYV CP/RTP & TuYV P1 & GSFR.ITIK $_{195}$ CQFHNPK.VDEE & AEFK.TIAK $_{284}$ SDK.GDVT & $0.00 \mathrm{E}+00$ & $0.00 \mathrm{E}+00$ \\
\hline
\end{tabular}

${ }^{\text {a }}$ Amino acid sequence of cross-linked peptides deduced from MS3 fragmentation and database searching. The four amino acids before and after each peptide are given as a reference, with peptide boundaries denoted by periods. $\mathrm{K}$ residue numbers indicate cross-linked lysines. The bolded peptides were found cross-linked in an unambiguous homodimer.

${ }^{\mathrm{b}}$ False discovery rates (FDR) for MS3 identification of the indicated peptides.

coat protein trimer. Previous cross-linking work with PLRV identified five unambiguous homodimer cross-links between PLRV coat protein monomers (Chavez et al., 2012; DeBlasio et al., 2015a). Of these, one was homologous to the TuYV K179-K179 cross-link, and one did not have a lysine at the homologous position in TuYV (Supplementary Table S1). Lysine residues in the TuYV coat protein homologous to the remaining three PLRV homodimer cross-links were used as additional distance constraints for modeling with SymmDock. Of the resulting 77 models for the TuYV coat protein trimer, two were selected based on their fit with the PLRV and TuYV cross-linking data, taking into account the shortest solvent accessible distance between the lysine pairs and similarity to previous models for luteovirid coat protein trimers (Brault et al., 2003; Chavez et al., 2012; DeBlasio et al., 2015a; Terradot et al., 2001).

Of the four previously proposed luteovirid trimer models, only the DeBlasio and Chavez/Cilia models were PIR-derived (Chavez et al., 2012; DeBlasio et al., 2015a). Of these two, the DeBlasio model was based on a greater number of cross-links, and these cross-links were also
A

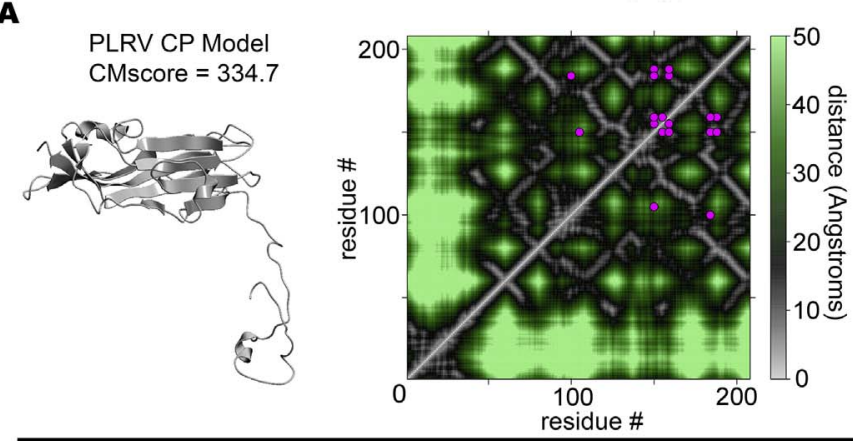

B

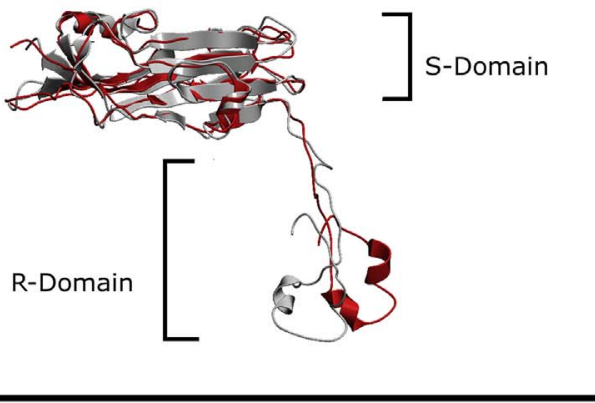

C
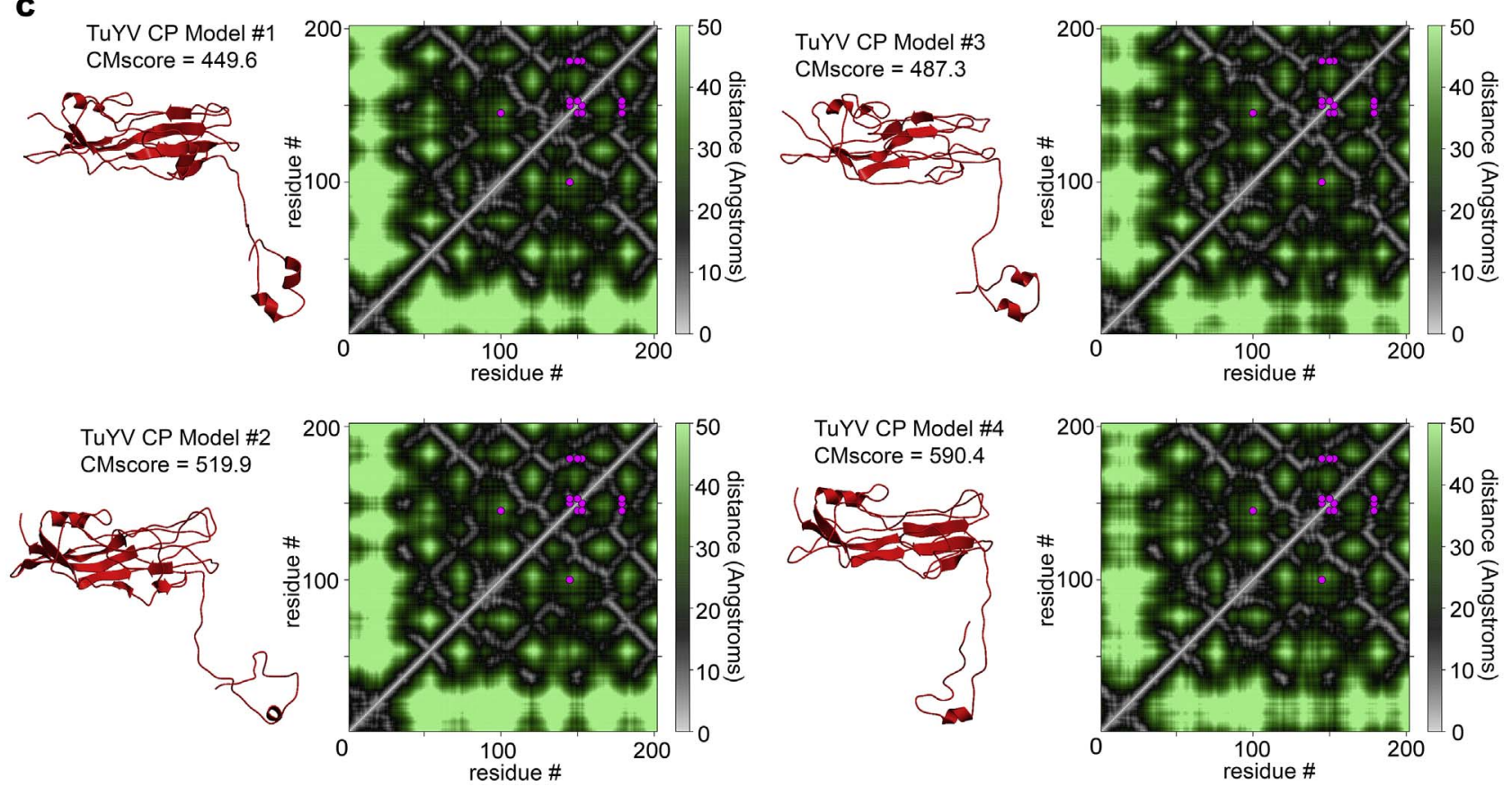



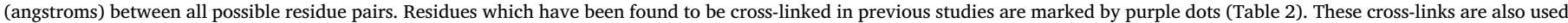

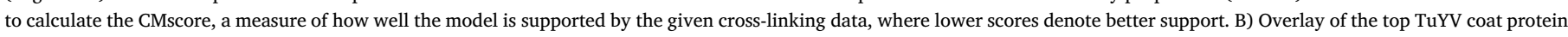

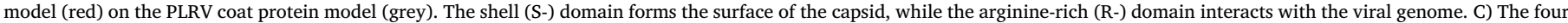

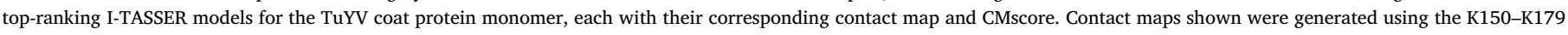


referred to the web version of this article.) 



Fig. 2. Comparison of cross-linking guided luteovirid trimer models. A) The most recent PLRV coat protein trimer model (DeBlasio et al., 2015a). B) TuYV trimer Model A. C) TuYV trimer Model B. All models are shown as viewed from the capsid exterior. Four lysine residues found cross-linked as unambiguous homodimers, used for generation of the models, are space-filled and shown in red, orange, blue, and purple. (For interpretation of the references to colour in this figure legend, the reader is referred to the web version of this article.)

used to guide modeling of the TuYV trimer. Therefore, comparisons of the TuYV trimer here and elsewhere in this study were performed against the DeBlasio model, except where otherwise noted. As shown in Fig. 2, Model A was most similar in shape to the PLRV trimer model. The S-domains project outward radially from the beta-annulus at a $\sim 120^{\circ}$ angle. The relative positions of the lysine residues used as distance constraints were also very similar to the PLRV model, indicating that the rotation of the monomers relative to the radial axis was also similar.

In contrast, Model B was the only one of the 77 SymmDock models to satisfy solvent-accessible distance constraints for all four lysine pairs, including the K179-K179 pair found cross-linked in TuYV samples. Model B is similar in shape to the trimeric asymmetric unit of other icosahedral viruses, including RGMoV and Rice yellow mottle virus (RYMV; Unclassified: Sobemovirus) - the nearest relatives for which crystal structures are available. The monomers in Model B are more tightly packed than in Model A, and are rotated, as shown by the difference in positioning of the reactive lysine residues.

Although Model B was the only model with all four unambiguous homodimers within acceptable solvent accessible distance constraints, it should be noted that a model can be correct without satisfying all distance constraints. A limitation of PIR and other cross-linking technologies is the inability to determine which region of the capsid any given cross-link was found in. While all four cross-links may occur near the trimer center, as presented here, it is also possible that one or more of these cross-links occurred at the interface between trimer units, at the five-fold axis of symmetry, or even in unincorporated coat protein dimers (DeBlasio et al., 2015a). For this reason it may not be advisable to dismiss or accept a model on the sole basis of the solventaccessible distance between residues. In this particular case it seems likely that all four cross-links occurred in the same area of the capsid, given their proximity to one another on the monomer model, but this cannot be determined with certainty.

The conformation of R-domain of the TuYV and PLRV coat proteins, which interacts with viral RNA inside the capsid, is markedly different between both the PLRV and TUYV coat protein trimer models. However, it is unlikely that the conformation of the R-domains can be accurately predicted, as modeling software cannot account for their interaction with viral nucleic acid inside the capsid. Protein-RNA interactions, such as in the R-domain, cannot yet be accurately modeled; the generated models instead assume a neutral aqueous environment surrounding the entire protein complex. This is likely a large part of the reason why there is so much variability in models for the R-domain, as evidenced by the top four I-TASSER models for the TuYV coat protein (Fig. 1).

\subsection{Comparison of epitope and critical residue locations between models}

The high degree of conservation between the PLRV and TuYV coat protein sequences permits the superimposition of data from both species on the TuYV trimer models. Residues previously identified in mutational studies as important for virion assembly in TuYV (red) and PLRV (yellow) map primarily to the center of the exterior surface of each S-domain in Model A, whereas in Model B these residues map more to the outer edges of the trimer (Fig. 3A, B). A 2005 study of PLRV identified a number of residues which, when mutated to alanine residues, completely abolished virion assembly (Lee et al., 2005). Four such residues, E170, W171, H172, and D177, were located at the predicted center of the capsid asymmetric unit and were hypothesized to stabilize the asymmetric unit via formation of a negatively charged depression. These residues are in a similar position in TuYV Model A, forming a small pit at the center of the asymmetric unit. In Model B, this pit is wider and occurs instead at the five- and three-fold axes of symmetry, and has an outer rim lined with the aforementioned EWH motif alternating with a short alpha helix created at one of the acidic patches - another highly conserved, charged region of the coat protein. As with the EWH motif, mutation of the KAY motif at the end of this helix (positions 100-102 in TuYV, or 105-107 in PLRV) completely blocks virion assembly (Kaplan et al., 2007).

Mutational studies in TuYV by Brault and colleagues found that a double substitution mutant, Q121E/N122D, conferred no measurable phenotype (Brault et al., 2003). Virions assembled normally and were aphid-transmissible. The authors noted that this was surprising, given 
A

PLRV_CP
TuYV_CP

PLRV CP

TuYv_CP

PLRV_CP

TuYV_CP

PLRV_CP

TUYV_CP

PLRV_CP

TUYV_CP
MSTVVVKGNV NGGVQQPRRR RRQSLRRRAN RVQPVVMV.T APGQPRRRRR MNTVVGRRII NG....RRRP RRQT..RRAQ RPQPVVVVQT SRATQRRPRR


RRRGNNRTGR TVPTRGAGSS ETFVFSKDNL AGSSSGAITF GPSLSDCPAF
45 45

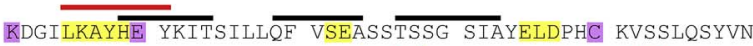
SNGMLKAYHE YKISMVILEF VSEASSQNSG SIAYELDPHC KLNSLSSTIN 95 115

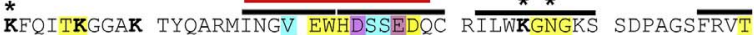
$\begin{array}{ll}\text { KFGITKPGKR AFTASYINGT EWHDVAEDOF } & \text { RILYKGNG.S } \\ 145 & \text { SSIAGSFRIT } \\ 165 & \end{array}$

\section{IRVALQNPK} IKCQFHNPK

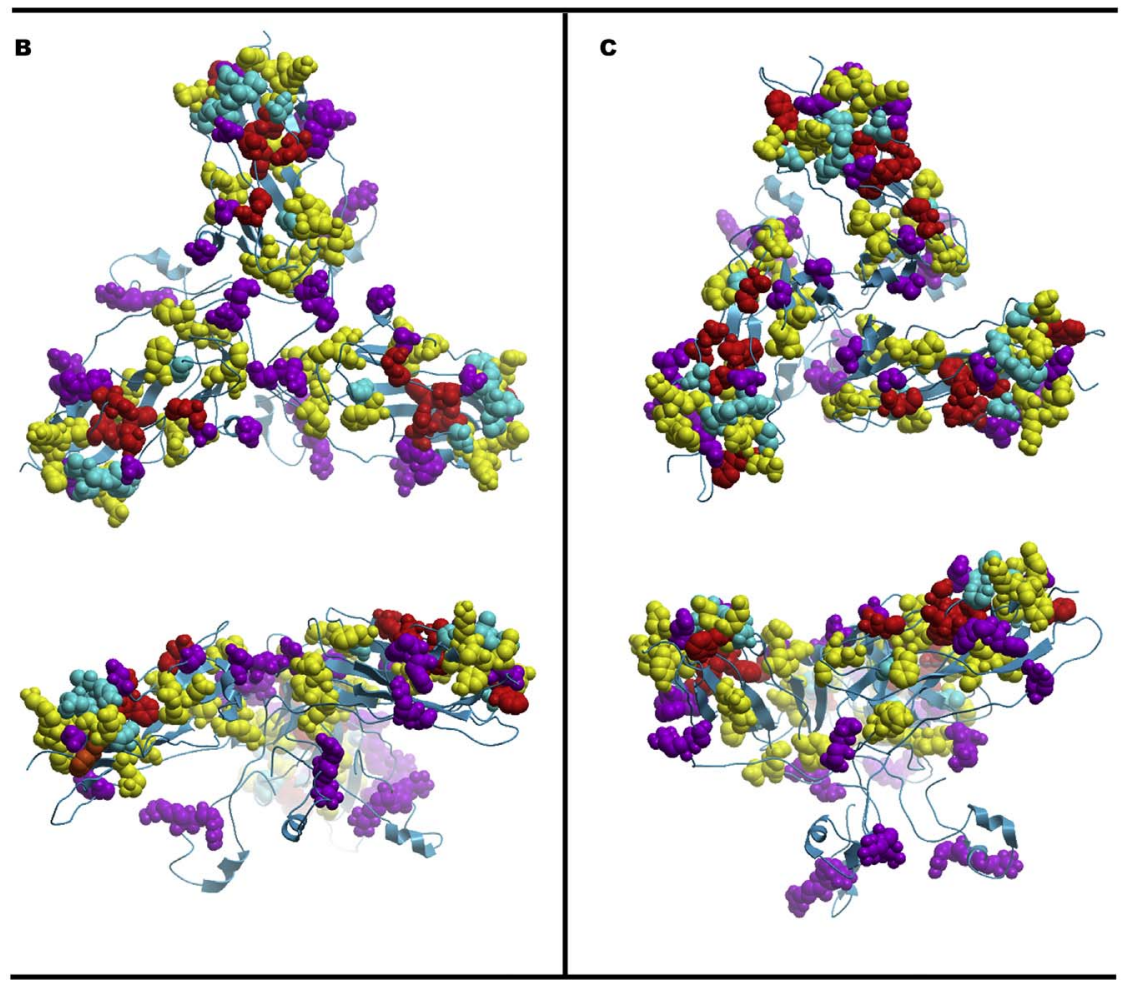

D
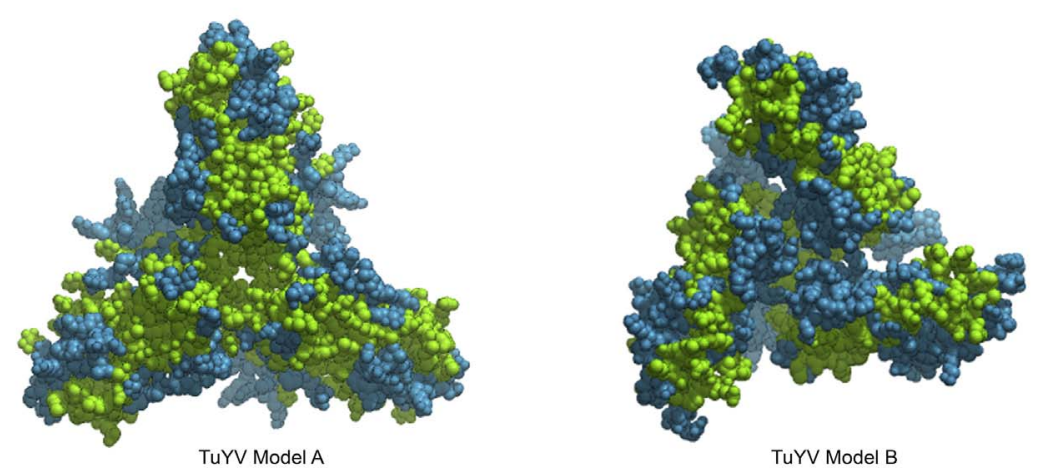

(caption on next page) 








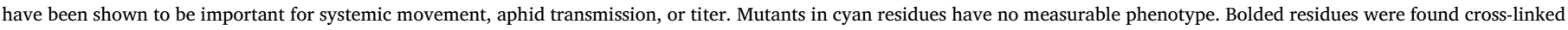

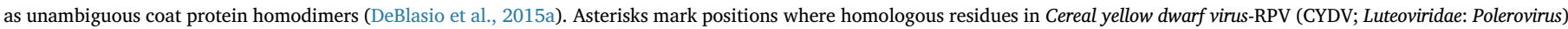

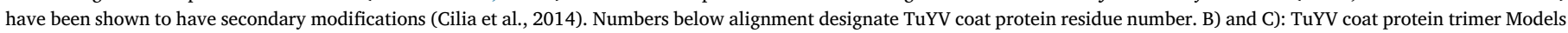

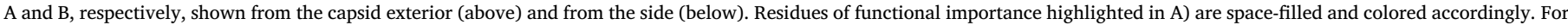



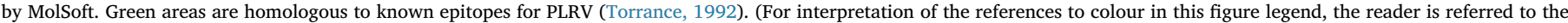
web version of this article.)

that the PLRV trimer model proposed by Terradot and colleagues, referred to as the Terradot model hereafter, predicts these residues to lie at the three- and five-fold axes of symmetry (Terradot et al., 2001). A double mutant within the Terradot structure would have to tolerate the presence of 10-12 negatively charged amino acids in proximity at 32 different places on the capsid. This incongruity also holds true for the DeBlasio PLRV model and TuYV Model A. However, in TuYV Model B these residues fall near the midpoint of the sides of the asymmetrical unit, on the underside of the trimer. In this case, the QN motifs from multiple monomers do not converge at any one point. The additional negative charges are spread out over a larger area, where they are more likely to be tolerated, and also partially face the positively-charged interior of the capsid. TuYV Model B is very similar in both shape and placement of the QN residues to the TuYV trimer model proposed by Brault et al. in light of their findings (Brault et al., 2003). Although there are significant differences in other aspects of the trimer structure between the Brault model and TuYV Model B, partially owing to major differences in the predicted structure of the coat protein monomer, the convergence of the two models in regards to the QN motif is nonetheless interesting.

In 1992, twelve regions of the PLRV coat protein were identified as solvent accessible based on epitope mapping (Torrance, 1992). Surprisingly, one such epitope was located at the coat protein $\mathrm{N}$-terminus, a region believed to be on the capsid interior. Another epitope in the Rdomain was found for Barley yellow dwarf virus (BYDV; Luteoviridae: Luteovirus) (Rizzo and Gray, 1992). A mechanism for solvent accessibility of these epitopes was first proposed by DeBlasio et al.: looser packing in the DeBlasio PLRV trimer model created an opening in the trimer center, through which the R-domains may be partially solvent exposed (DeBlasio et al., 2015a). The looser packing of monomers in TuYV Model A creates a similar opening, while the tighter packing in Model B does not (Fig. 3C). Additional support for partial or conditional solvent exposure of the coat protein R-domain comes from PIR-assisted modeling of a direct interaction between the PLRV coat protein and a host luminal binding protein (BiP) (DeBlasio et al., 2015a). A stretch of seven hydrophobic amino acids in the coat protein R-domain, homologous to the known binding site for human BiP-family proteins, was shown to fit in the substrate binding pocket of the $N$. benthamiana BiP. These hydrophobic amino acids, an anomaly in a region otherwise highly charged, are well conserved across luteovirid species (DeBlasio et al., 2015a). In both Models A and B, at least one epitope other than the N-terminal epitope is located on the interior side of the trimer. This may be attributed to the interaction of soluble, non-incorporated readthrough protein with virions (Boissinot et al., 2014).

\subsection{Comparison of models in the context of the capsid}

Although the shape of Model B appears to be more similar to the PLRV trimer model computationally derived by Terradot and colleagues (Terradot et al., 2001), mapping both models to a more three-dimensional projection reveals that the orientation of the monomers in the Terradot PLRV model is actually more similar to TuYV Model A, as well as the DeBlasio PLRV model (DeBlasio et al., 2015a). The visual difference between the models lies primarily in which unit of three monomers is denoted the "trimer": the DeBlasio PLRV model and TuYV Model A place the center of the trimer unit at the three-fold axis of symmetry, such that the monomers in the trimer are each in a different face of the capsid. The three monomers in these models are all in equivalent contexts, but account for, at most, two-thirds of the monomers in the capsid, assuming that the second trimer unit at the three-fold axis is identical to the first (Fig. 4A, B). The remaining third of the monomers are located at the five-fold axes of symmetry, which are not contained within these models, but could be similarly oriented. In contrast, the Terradot PLRV model, TuYV Model B, and the RYMV crystal structure place the center of the trimer at the quasi-three-fold axis of symmetry, such that the trimer is effectively the asymmetric unit of the capsid (Fig. 4C, D). These models contain all three quasiequivalent monomers and therefore all of the monomers in the capsid, but they do not model the relationship between capsid faces at the three- or five- fold axes of symmetry. Importantly, the orientation of the monomers relative to the quasi-three-fold axes of symmetry is similar in the Terradot and DeBlasio PLRV models, and in TuYV Model A. This can be visualized more easily by highlighting the position of a tryptophan residue found to be critical for virion assembly in both TuYV and PLRV (W166/W178, respectively, Fig. 4) (Brault et al., 2003; Lee et al., 2005). The Terradot and DeBlasio PLRV models, and TuYV Model A, have the aforementioned tryptophan residue positioned at the quasithree-fold axis. However, in TuYV Model B, residue W166 is instead positioned at the three- and five-fold axes of symmetry. Thus, the orientation of the monomers in Model B relative to the quasi-three-fold axis is the inverse of the other models.

As an alternative to choosing either Model A or B for the TuYV coat protein trimer, a hybrid of both could be proposed, with two subunits from Model A and one from Model B. In this case one would also expect to find cross-links between residues at opposite ends of the S-domain. Such cross-links were, in fact, among those found in a previous PIR study with PLRV (e.g. K100-K184) (DeBlasio et al., 2015a), but were not used for trimer modeling because it could not be determined whether they were intra- or inter-protein cross-links.

\subsection{Direct interaction of a luteovirid non-structural protein with the coat protein}

The cross-linked residue in ORF1 is present in both the P1 polyprotein and the P1-P2 fusion protein, but is located in a serine protease domain present in both proteins. The finding of a direct interaction between the TuYV coat protein and P1 protease domain supports the hypothesis that readthrough protein truncation is performed by the viral protease, as discussed in Section 1. Although no cross-links were detected between P1 and the readthrough domain of the readthrough protein, the proximity between P1 and the capsid surface during cleavage could easily account for the coat protein-P1 interaction. Additionally, the low abundance of the readthrough protein compared to coat protein in purified samples makes it difficult to detect any interactions with the readthrough domain, as evidenced by the low number of cross-links involving the readthrough domain that have been identified for PLRV (Chavez et al., 2012; DeBlasio et al., 2015a).

To determine the plausibility of P1 truncation of the luteovirid readthrough protein, the distribution of putative cleavage sites in luteovirid readthrough proteins was assessed. Although the only experimentally verified P1 cleavage site for a luteovirid is a gluta- 
$\mathbf{A}$

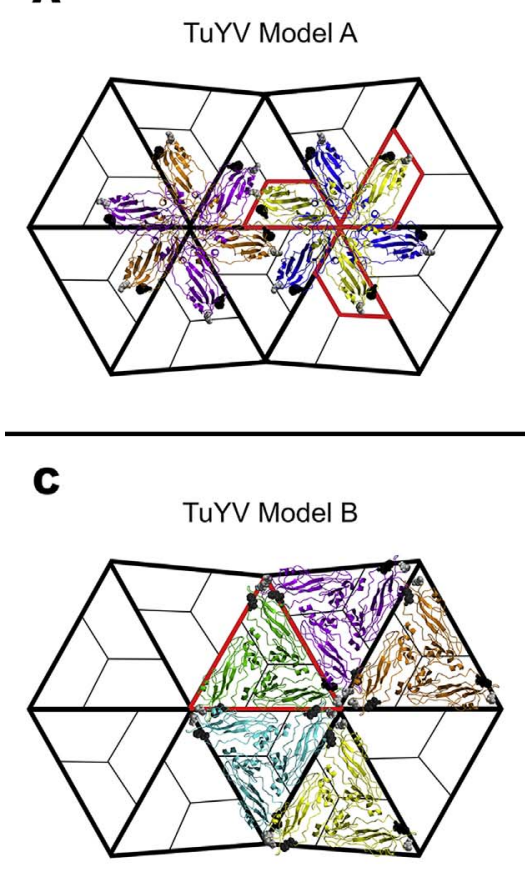

B

PLRV (DeBlasio Model)

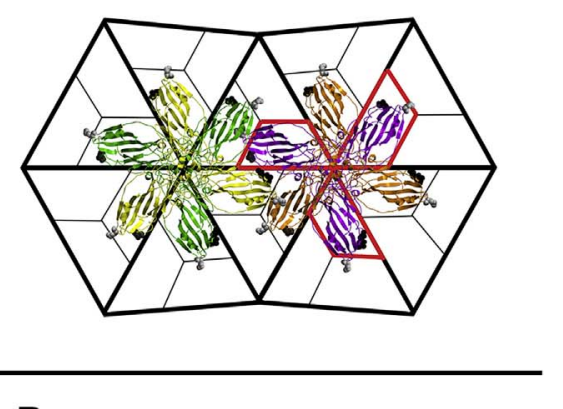

D



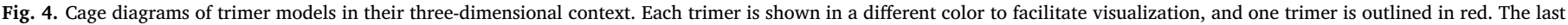

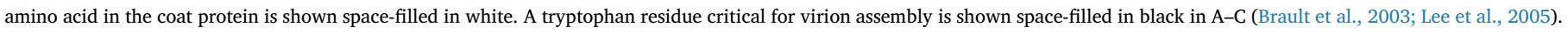

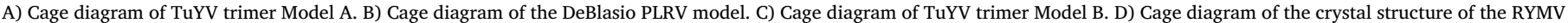

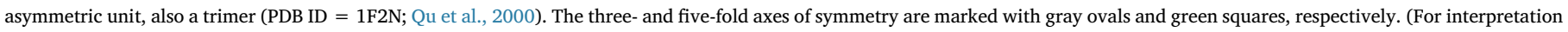
of the references to colour in this figure legend, the reader is referred to the web version of this article.)

mate $_{204}$-arginine $_{205}$ (ER) motif in the PLRV polyprotein, a putative second glutamate-serine (ES) site has been identified based on the estimated sizes of the polyprotein cleavage products (Li et al., 2007; Prüfer et al., 1999). This agrees with literature showing that closely related sobemovirus proteases cleave at ES, glutamate-threonine (ET), and glutamate-asparagine (EN) sites in their corresponding polyproteins (Makinen et al., 2000; Nair and Savithri, 2010; Satheshkumar et al., 2004). An ER cleavage site in the related Sesbania mosaic virus (SeMV; Unclassified: Sobemovirus) has also been proposed, but not yet verified (Nair and Savithri, 2010). Both luteovirid and sobemovirus proteases are believed to cleave between the two amino acids comprising the recognition site. The 3C-like serine proteases from the more distant genus Arterivirus cleave at (E/Q)-(G/S/A/N/K) sites in their respective polyproteins (Snijder and Gorbalenya, 2012). Additionally, it has been noted for PLRV, SeMV, and Lactate dehydrogenase-elevating virus (LDV; Nidovirales: Arteriviridae: Arterivirus) that the one or two amino acids immediately following the diresidue cleavage site are often aliphatic (Godeny et al., 1993; Li et al., 2007; Nair and Savithri, 2010). To determine the most likely cleavage sites in other luteovirid species, a multiple sequence alignment of the PLRV P1 polyprotein and the P1 polyproteins of other luteovirids was generated (supplementary materials). Using this alignment and the preferences of the aforementioned proteases, the luteovirid P1 cleavage motif was tentatively hypothesized to be (E)-(R/K/S/T/I)-(X), where $\mathrm{X}$ is a small aliphatic or polar amino acid. To assess the distribution of putative cleavage sites in luteovirid readthrough proteins, readthrough protein consensus sequences were generated for thirty luteovirid species and searched for sites satisfying the above criteria (supplementary materials). A probability density plot of putative P1 cleavage sites by the molecular weight of the resulting putative truncated readthrough proteins is shown in Fig. 5B. Molecular weight, rather than amino acid position, was chosen as a basis for comparison due to the relatively poor conservation of readthrough protein sequence across luteovirid species. Although the criteria used to identify potential P1 cleavage sites in the readthrough protein are only an estimate based on available data, a striking pattern in the distribution of putative cleavage sites in the luteovirid consensus sequences could be seen. Putative sites were found most frequently in the $\mathrm{C}$-terminal $\sim 25 \mathrm{kDa}$ of the readthrough protein, generating truncated products between 50 and $75 \mathrm{kDa}$ in size. This corresponds remarkably with the typical size estimates for luteovirid truncated readthrough protein isoforms, between 50 and $70 \mathrm{kDa}$ (Fig. 5A). In contrast, there are relatively few predicted products in the $0-50 \mathrm{kDa}$ range. The dramatic difference in prevalence of putative cleavage sites beginning around $50 \mathrm{kDa}$ suggests that the distribution of these sites is not random, particularly given the relative dearth of putative cleavage sites in the coat protein, which is required for virion assembly and readthrough protein incorporation.

These cleavage site predictions are interesting overall, but it should be noted that they likely represent a simplified view, even if the P1 protease is responsible for truncation. Accessibility of putative cleavage sites may be affected by post-translational modifications or conformation of the readthrough protein. Additionally, P1 protease site preferences may vary by virus species or the presence and conformation of the adjacent VPg, as has been shown for sobemoviruses (Makinen et al., 2000; Nair et al., 2008; Nair and Savithri, 2010; Satheshkumar et al., 2005; Satheshkumar et al., 2004). Of course, readthrough protein truncation by host proteases, at sites either disparate from or similar to the P1 cleavage motifs proposed here, cannot be ruled out. Significant further work is necessary to determine the mechanism behind truncation of the readthrough protein. However, the finding of a direct interaction between the TuYV coat protein and protease domain of the P1 polyprotein, together with the striking similarity in the distribution of putative P1 cleavage sites to the estimated sizes of truncated readthrough protein isoforms, suggest involvement of the viral protease. The P1 polyprotein and the P1-P2 fusion protein were both found to co-immunoprecipitate with PLRV in samples extracted from infected $N$. benthamiana leaves (DeBlasio et al., 2015b). PLRV P1 was also found to co-immunoprecipitate with PLRV in protein extracts 
A

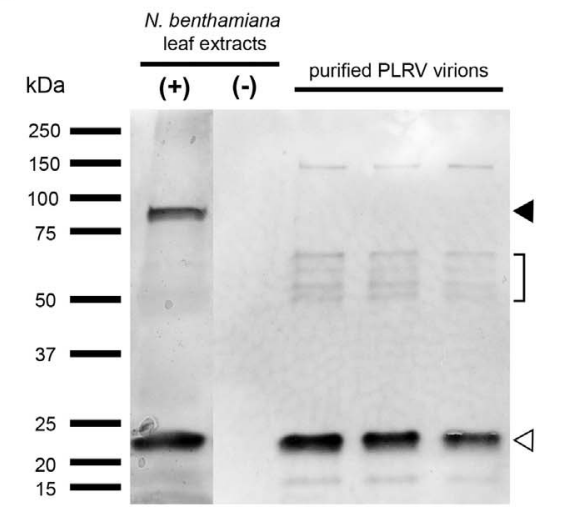

$\mathbf{B}$



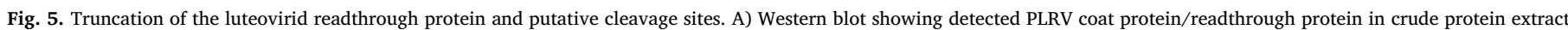

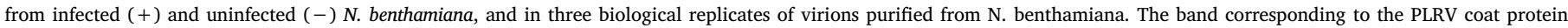

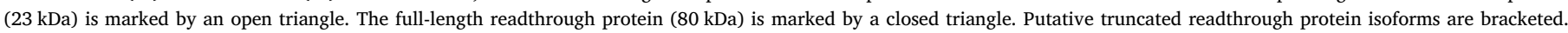

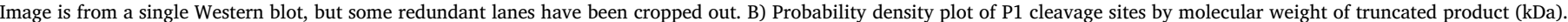
Shaded area represents the area under the smoothed Gaussian kernel density curve.

from systemically infected potato (S. tuberosum), a natural host of PLRV (DeBlasio et al., 2016).

\section{Conclusion}

Application of PIR technology to TuYV provided direct experimental evidence that cross links, and therefore protein topologies, can be highly conserved between species. This finding opens opportunities for broader application of cross-linking data; for example, the PLRV and TuYV coat protein cross-links reported here and previously may also be useful for modeling of other luteovirid coat protein trimers. The similarity in coat protein topology between PLRV and TuYV also implies that the comprehensive mutational and epitope mapping studies which have been performed in the most commonly studied luteovirid species can be extended to the many economically important luteovirids which are poorly understood.

\section{Acknowledgements}

The authors would like to thank Jason Ingram, Rogerio Santos, August Kronstadt-Brennan, and Brian Bell for excellent aphid and plant care at Cornell University. We also thank Jimmy Eng and the staff at the University of Washington Proteome Resource (UWPR) center.

Funding for this work was provided by the National Science Foundation (NSF grant number 1354309) and the United States Department of Agriculture - National Institute of Food and Agriculture (USDA-NIFA grant number 1008590).

\section{Appendix A. Supplementary data}

Supplementary data associated with this article can be found, in the online version, at http://dx.doi.org/10.1016/j.virusres.2017.05.005.

\section{References}

Adams, M.J., Lefkowitz, E.J., King, A.M., Harrach, B., Harrison, R.L., Knowles, N.J., Kropinski, A.M., Krupovic, M., Kuhn, J.H., Mushegian, A.R., Nibert, M., Sabanadzovic, S., Sanfacon, H., Siddell, S.G., Simmonds, P., Varsani, A., Zerbini, F.M., Gorbalenya, A.E., Davison, A.J., 2016. Ratification vote on taxonomic proposals to the International Committee on Taxonomy of Viruses. Arch. Virol. 161 (10), 2921-2949.

Bag, S., Al Rwahnih, M., Li, A., Gonzalez, A., Rowhani, A., Uyemoto, J.K., Sudarshana, M.R., 2015. Detection of a new luteovirus in imported nectarine trees: a case study to propose adoption of metagenomics in post-entry quarantine. Phytopathology 105 (6), $840-846$.
Bahner, I., Lamb, J., Mayo, M.A., Hay, R.T., 1990. Expression of the genome of Potato leafroll virus: readthrough of the coat protein termination codon in vivo. J. Gen. Virol. 71 (Pt. 10), 2251-2256.

Bejerman, N., Giolitti, F., Trucco, V., de Breuil, S., Dietzgen, R.G., Lenardon, S., 2016. Complete genome sequence of a new enamovirus from Argentina infecting alfalfa plants showing dwarfism symptoms. Arch. Virol. 161 (7), 2029-2032.

Boissinot, S., Erdinger, M., Monsion, B., Ziegler-Graff, V., Brault, V., 2014. Both structural and non-structural forms of the readthrough protein of Cucurbit aphid-borne yellows virus are essential for efficient systemic infection of plants. PLoS One 9 (4), 1-10.

Brault, V., van den Heuvel, J.F.J.M., Verbeek, M., Ziegler-Graff, V., Reutenauer a. Herrbach, E., Garaud, J.C., Guilley, H., Richards, K., Jonard, G., 1995. Aphid transmission of Beet western yellows luteovirus requires the minor capsid read-through protein P74. EMBO J. 14 (4), 650-659.

Brault, V., Bergdoll, M., Mutterer, J., Prasad, V., Pfeffer, S., Erdinger, M., Richards, K.E., Ziegler-Graff, V., 2003. Effects of point mutations in the major capsid protein of Beet western yellows virus on capsid formation, virus accumulation, and aphid transmission. J. Virol. 77 (5), 3247-3256.

Bruyère, A., Brault, V., Ziegler-Graff, V., Simonis, M.-T., van den Heuvel, J.F.J.M., Richards, K., Guilley, H., Jonard, G., Herrbach, E., 1997. Effects of mutations in the Beet western yellows virus readthrough protein on its expression and packaging and on virus accumulation, symptoms, and aphid transmission. Virology 230 (2), 323-334.

Chapman, B.A., Chang, J.T., 2000. Biopython: python tools for computational biology. ACM SIGBIO Newslett. 20, 15-19.

Chavez, J.D., Cilia, M., Weisbrod, C.R., Ju, H.-J., Eng, J.K., Gray, S.M., Bruce, J.E., 2012 Cross-linking measurements of the Potato leafroll virus reveal protein interaction topologies required for virion stability, aphid transmission, and virus-plant interactions. J. Proteome Res. 11 (5), 2968-2981.

Chay, C.A., Gunasinge, U.B., Dinesh-Kumar, S.P., Miller, W.A., Gray, S.M., 1996. Aphid transmission and systemic plant infection determinants of Barley yellow dwarf luteovirus-PAV are contained in the coat protein readthrough domain and $17-\mathrm{kDa}$ protein, respectively. Virology 219 (1), 57-65.

Chen, S., Jiang, G., Wu, J., Liu, Y., Qian, Y., Zhou, X., 2016. Characterization of a novel polerovirus infecting maize in China. Viruses 8 (5), 1-17.

Cheng, S.L., Domier, L.L., D'Arcy, C.J., 1994. Detection of the readthrough protein of Barley yellow dwarf virus. Virology 202 (2), 1003-1006.

DeBlasio, S.L., Chavez, J.D., Alexander, M.M., Ramsey, J., Eng, J.K., Mahoney, J., Gray, S.M., Bruce, J.E., Cilia, M., 2015a. Visualization of host-polerovirus interaction topologies using Protein Interaction Reporter technology. J. Virol. 90 (4), 1973-1987.

DeBlasio, S.L., Johnson, R., Mahoney, J., Karasev, A., Gray, S.M., MacCoss, M.J., Cilia, M., 2015b. Insights into the polerovirus-plant interactome revealed by coimmunoprecipitation and mass spectrometry. Mol. Plant Microbe Interact. 28 (4), $467-481$.

DeBlasio, S.L., Johnson, R.S., MacCoss, M.J., Gray, S.M., Cilia, M., 2016. Model systemguided protein interaction mapping for virus isolated from phloem tissue. J. Proteome Res. 15 (12), 4601-4611.

Dinesh-Kumar, S.P., Brault, V., Miller, W.A., 1992. Precise mapping and in vitro translation of a trifunctional subgenomic RNA of Barley yellow dwarf virus. Virology 187 (2), 711-722.

Filichkin, S.A., Lister, R.M., McGrath, P.F., Young, M.J., 1994. In vivo expression and mutational analysis of the Barley yellow dwarf virus readthrough gene. Virology 205 (1), 290-299.

Godeny, E.K., Chen, L., Kumar, S.N., Methven, S.L., Koonin, E.V., Brinton, M.A., 1993. Complete genomic sequence and phylogenetic analysis of the Lactate dehydrogenaseelevating virus (LDV). Virology 194 (2), 585-596.

Gray, S.M., Cilia, M., Ghanim, M., 2014. Circulative, nonpropagative virus transmission: 
an orchestra of virus-, insect-, and plant-derived instruments. Adv. Virus Res. 89, 141-199.

Hipper, C., Monsion, B., Bortolamiol-Bécet, D., Ziegler-Graff, V., Brault, V., 2014. Formation of virions is strictly required for Turnip yellows virus long-distance movement in plants. J. Gen. Virol. 95 (Pt. 2), 496-505.

Holsters, M., Silva, B., Van Vliet, F., Genetello, C., De Block, M., Dhaese, P., Depicker, A., Inzé, D., Engler, G., Villarroel, R., Van Montagu, M., Schell, J., 1980. The functional organization of the nopaline A. tumefaciens plasmid pTiC58. Plasmid 3 (2), 212-230.

Ibaba, J.D., Laing, M.D., Gubba, A., 2017. Pepo aphid-borne yellows virus: a new species in the genus Polerovirus. Virus Genes 53 (1), 134-136.

Jolly, C.A., Mayo, M.A., 1994. Changes in the amino acid sequence of the coat protein readthrough domain of Potato leafroll luteovirus affect the formation of an epitope and aphid transmission. Virology 201 (1), 182-185.

Kahraman, A., Malmström, L., Aebersold, R., 2011. Xwalk: computing and visualizing distances in cross-linking experiments. Bioinformatics 27 (15), 2163-2164.

Kaplan, I.B., Lee, L., Ripoll, D.R., Palukaitis, P., Gildow, F., Gray, S.M., 2007. Point mutations in the Potato leafroll virus major capsid protein alter virion stability and aphid transmission. J. Gen. Virol. 88 (Pt. 6), 1821-1830.

Kim, J.H., Jander, G., 2007. Myzus persicae (green peach aphid) feeding on Arabidopsis induces the formation of a deterrent indole glucosinolate. Plant J. 49 (6), 1008-1019.

Lee, L., Kaplan, I.B., Ripoll, D.R., Liang, D., Palukaitis, P., Gray, S.M., 2005. A surface loop of the Potato leafroll virus coat protein is involved in virion assembly, systemic movement, and aphid transmission. J. Virol. 79 (2), 1207-1214.

Leiser, R.M., Ziegler-Graff, V., Reutenauer, A., Herrbach, E., Lemaire, O., Guilley, H., Richards, K., Jonard, G., 1992. Agroinfection as an alternative to insects for infecting plants with Beet western yellows luteovirus. Proc. Natl. Acad. Sci. U. S. A. 89 (19), 9136-9140.

Li, X., Ryan, M.D., Lamb, J.W., 2000. Potato leafroll virus protein P1 contains a serine proteinase domain. J. Gen. Virol. 81 (Pt. 7), 1857-1864.

Li, X., Halpin, C., Ryan, M.D., 2007. A novel cleavage site within the Potato leafroll virus P1 polyprotein. J. Gen. Virol. 88 (Pt. 5), 1620-1623.

Linz, L.B., Liu, S., Chougule, N.P., Bonning, B.C., 2015. In vitro evidence supports aminopeptidase $\mathrm{N}$ as a receptor for a plant virus in the pea aphid vector. J. Virol. 89 (22), 11203-11212.

Lotos, L., Maliogka, V.I., Katis, N.I., 2016. New poleroviruses associated with yellowing symptoms in different vegetable crops in Greece. Arch. Virol. 161 (2), 431-436.

Makinen, K., Makelainen, K., Arshava, N., Tamm, T., Merits, A., Truve, E., Zavriev, S., Saarma, M., 2000. Characterization of VPg and the polyprotein processing of Cocksfoot mottle virus (genus Sobemovirus). J. Gen. Virol. 81 (Pt. 11), 2783-2789.

Mashiach-Farkash, E., Nussinov, R., Wolfson, H.J., 2011. SymmRef: a flexible refinement method for symmetric multimers. Proteins 79 (9), 2607-2623.

Nair, S., Savithri, H.S., 2010. Processing of SeMV polyproteins revisited. Virology 396 (1), 106-117.

Nair, S., Gayathri, P., Murthy, M.R., Savithri, H.S., 2008. Stacking interactions of W271 and H275 of SeMV serine protease with W43 of natively unfolded VPg confer catalytic activity to protease. Virology 382 (1), 83-90.

Navare, Arti T., Chavez Juan, D., Zheng, C., Weisbrod Chad, R., Eng Jimmy, K., Siehnel, R., Singh Pradeep, K., Manoil, C., Bruce James, E., 2015. Probing the protein interaction network of Pseudomonas aeruginosa cells by chemical cross-linking mass spectrometry. Structure 23 (4), 762-773.

Peter, K.A., Liang, D., Palukaitis, P., Gray, S.M., 2008. Small deletions in the Potato leafroll virus readthrough protein affect particle morphology, aphid transmission, virus movement and accumulation. J. Gen. Virol. 89 (Pt. 8), 2037-2045.

Peter, K.A., Gildow, F.E., Palukaitis, P., Gray, S.M., 2009. The C terminus of the polerovirus $\mathrm{P} 5$ readthrough domain limits virus infection to the phloem. J. Virol. 83 (11), 5419-5429.

Prüfer, D., Kawchuk, L., Monecke, M., Nowok, S., Fischer, R., Rohde, W., 1999. Immunological analysis of Potato leafroll luteovirus (PLRV) P1 expression identifies a $25 \mathrm{kDa}$ RNA-binding protein derived via P1 processing. Nucleic Acids Res. 27 (2), 421-425.

Qu, C., Liljas, L., Opalka, N., Brugidou, C., Yeager, M., Beachy, R.N., Fauquet, C.M., Johnson, J.E., Lin, T., 2000. 3D domain swapping modulates the stability of members of an icosahedral virus group. Structure 8 (10), 1095-1103.

Reinbold, C., Herrbach, E., Brault, V., 2003. Posterior midgut and hindgut are both sites of acquisition of Cucurbit aphid-borne yellows virus in Myzus persicae and Aphis gossypii. J. Gen. Virol. 84 (Pt. 12), 3473-3484.

Reutenauer, A., Ziegler-Graff, V., Lot, H., Scheidecker, D., Guilley, H., Richards, K., Jonard, G., 1993. Identification of Beet western yellows luteovirus genes implicated in viral replication and particle morphogenesis. Virology 195 (2), 692-699.

Rizzo, T.M., Gray, S.M., 1992. Localization of a surface domain of the capsid protein of Barley yellow dwarf virus. Virology 186 (1), 300-302.

Rossmann, M.G., 2013. Structure of viruses: a short history. Q. Rev. Biophys. 46 (2), 133-180.

Satheshkumar, P.S., Lokesh, G.L., Savithri, H.S., 2004. Polyprotein processing: cis and trans proteolytic activities of Sesbania mosaic virus serine protease. Virology 318 (1), 429-438.

Satheshkumar, P.S., Gayathri, P., Prasad, K., Savithri, H.S., 2005. Natively unfolded VPg is essential for Sesbania mosaic virus serine protease activity. J. Biol. Chem. 280 (34), 30291-30300.

Schneidman-Duhovny, D., Inbar, Y., Nussinov, R., Wolfson, H.J., 2005. PatchDock and SymmDock: servers for rigid and symmetric docking. Nucleic Acids Res. 33 (Web Server Issue), W363-W367.

Schweppe, D.K., Chavez, J.D., Bruce, J.E., 2016. XLmap: an R package to visualize and score protein structure models based on sites of protein cross-linking. Bioinformatics 32 (2), 306-308.

Sharman, M., Kehoe, M., Coutts, B., van Leur, J., Filardo, F., Thomas, J., 2016. Two complete genome sequences of a Phasey bean mild yellows virus, a novel member of the Luteoviridae from Australia. Genome Announc. 4 (1).

Snijder, E.J., Gorbalenya, A.E., 2012. Arterivirus serine endopeptidase. In: Barrett, A.J., Rawlings, N.D., Woessner, J.F. (Eds.), Handbook of Proteolytic Enzymes, 3 ed. Academic Press, San Diego, CA, pp. 3137-3141.

Tang, X., Munske, G.R., Siems, W.F., Bruce, J.E., 2005. Mass spectrometry identifiable cross-linking strategy for studying protein-protein interactions. Anal. Chem. 77 (1), 311-318.

Terradot, L., Souchet, M., Tran, V., Giblot Ducray-Bourdin, D., 2001. Analysis of a threedimensional structure of Potato leafroll virus coat protein obtained by homology modeling. Virology 286 (1), 72-82.

Torrance, L., 1992. Analysis of epitopes on Potato leafroll virus capsid protein. Virology 191 (1), 485-489.

van den Heuvel, J.F.J.M., Boerma, T.M., Peters, D., 1991. Transmission of Potato leafroll virus from plants and artificial diets by Myzus persicae. Phytopathology 81 (2), $150-154$.

Veidt, I., Lot, H., Leiser, M., Scheidecker, D., Guilley, H., Richards, K., Jonard, G., 1988 Nucleotide sequence of Beet western yellows virus RNA. Nucleic Acids Res. 16 (21), 9917-9932.

Veidt, I., Bouzoubaa, S.E., Leiser, R.M., Ziegler-Graff, V., Guilley, H., Richards, K., Jonard, G., 1992. Synthesis of full-length transcripts of Beet western yellows virus RNA messenger properties and biological activity in protoplasts. Virology 186 (1), $192-200$.

Villamor, D.E., Mekuria, T.A., Pillai, S.S., Eastwell, K.C., 2016. High-throughput sequencing identifies novel viruses in nectarine: insights to the etiology of stempitting disease. Phytopathology 106 (5), 519-527.

Wang, J.Y., Chay, C., Gildow, F.E., Gray, S.M., 1995. Readthrough protein associated with virions of Barley yellow dwarf luteovirus and its potential role in regulating the efficiency of aphid transmission. Virology 206 (2), 954-962.

Weisbrod, C.R., Chavez, J.D., Eng, J.K., Yang, L., Zheng, C., Bruce, J.E., 2013. In vivo protein interaction network identified with a novel real-time cross-linked peptide identification strategy. J. Proteome Res. 12 (4), 1569-1579.

Wickham, H., 2009. ggplot2: Elegant graphics for data analysis, 1 ed. Use R! VIII Springer-Verlag, New York 213 pp.

Yang, J., Yan, R., Roy, A., Xu, D., Poisson, J., Zhang, Y., 2015. The I-TASSER Suite: protein structure and function prediction. Nat. Methods 12 (1), 7-8.

Ziegler-Graff, V., Brault, V., Mutterer, J.D., Simonis, M.-T., Herrbach, E., Guilley, H., Richards, K.E., Jonard, G., 1996. The coat protein of Beet western yellows luteovirus is essential for systemic infection but the viral gene products P29 and P19 are dispensable for systemic infection and aphid transmission. Mol. Plant Microbe Interact. 9 (6), 501-510. 